\title{
Double blind trial of recombinant human erythropoietin in preterm infants
}

United Medical and Dental Schools of Guy's and St Thomas's Hospitals, St Thomas's Campus, London, Department of Neonatal Paediatrics A J B Emmerson C M M Stern

\section{Department of Haematology} T C Pearson

Cilag Ltd, High Wycombe $\mathrm{H}$ J Coles

Correspondence to: Dr A J B Emmerson, Department of Paediatrics, St Thomas's Hospital, Lambeth Palace Road, London SE1 7EH.

Accepted 17 September 1992

No reprints available.

A J B Emmerson, H J Coles, C M M Stern, T C Pearson

\begin{abstract}
Twenty four infants between 27 and 33 weeks' gestation were recruited into a double blind study to investigate the use of recombinant human erythropoietin (r-HuEpo) for the prevention of anaemia of prematurity. Between 50 and $150 \mathrm{U}$ of r-HuEpo $(n=16)$ or placebo was administered subcutaneously twice a week from 7 days of age until discharge. There was a significant increase in the reticulocyte count in infants receiving r-HuEpo sustained from the second week of treatment until discharge compared with placebo. There was a reduction in the number of transfusions required in the $\mathbf{r}-\mathrm{HuEpo}$ group with only $47 \%$ requiring a transfusion compared with $87 \%$ in the placebo group. During treatment with r-HuEpo there was a significant rise in the red cell folate concentration, a significant fall in the ferritin concentration, and a significantly higher percentage of haemoglobin F at discharge suggesting active erythropoiesis. The study provides strong evidence for the efficacy of $\mathrm{r}$-HuEpo in stimulating erythropoiesis and reducing the requirement for transfusions for anaemia of prematurity.
\end{abstract}

(Arch Dis Child 1993;68:291-296)

Anaemia of prematurity presents at around 6 weeks of age and has an increased incidence and is more profound with greater prematurity. ${ }^{1}$ The aetiology of this anaemia is not clearly defined, although there is evidence for a disproportionately low endogenous erythropoietin concentration in anaemic preterm infants compared with anaemic adults or children. ${ }^{2}$ The reason for the low erythropoietin concentration in the presence of anaemia has not yet been elucidated, although it might relate to increased oxygen delivery to the tissues after delivery ${ }^{3}$ or to an insensitivity of the regulation mechanism. ${ }^{4}$ There is evidence from cell culture studies of erythroid precursors from anaemic preterm infants that there are adequate numbers of both circulating ${ }^{5}$ and marrow resident ${ }^{7}$ precursors which are responsive to exogenous erythropoietin. Anaemia of prematurity presenting at around 6 weeks of age must be clearly separated from the early anaemia seen in sick premature infants during the first weeks of life. This early anaemia has many causes, the requirement for frequent blood sampling for monitoring being the common- est. ${ }^{8}$ The consequences of anaemia of prematurity are significant, with tachycardia, tachypnoea, apnoea and poor feeding, leading to a requirement for blood transfusion. ${ }^{9}$ There are well recognised complications of blood transfusion that include infection with cytomegalovirus ${ }^{10}$ and the suppression of natural erythropoiesis after transfusion with adult haemoglobin, which leads to a worsened anaemia. ${ }^{11}$

After the cloning of the erythropoietin gene in $1985,{ }^{12}$ leading to the availability of recombinant human erythropoietin (r-HuEpo), it has been postulated that r-HuEpo may be useful for the prevention or treatment of anaemia in premature infants. Early pilot studies in anaemic preterm infants have suggested that r-HuEpo may indeed have a stimulatory effect on red cell production, with a rise in the reticulocyte count, though the efficacy of r-HuEpo in reducing the need for transfusion has not yet been proved. ${ }^{13}$ In many of these studies, r-HuEpo treatment has been initiated when the infant was already anaemic, and a significant reduction in the number of transfusions was not shown. In the current study it was postulated that early administration of r-HuEpo would stimulate erythropoiesis before the development of anaemia of prematurity. In addition the early use of erythropoietin would reduce the number of transfusions required. Therefore we undertook a double blind placebo controlled study to investigate the safety and efficacy of $r$-HuEpo for the prevention of anaemia of prematurity, commencing the r-HuEpo treatment or placebo at around 7 days of age.

\section{Subjects and methods}

Signed informed consent was obtained during the first week of life from one or both parents of 24 infants ( 10 boys, 14 girls) born between 27 and 33 weeks' gestation. Infants were excluded from the study if they showed signs of a primary haematological disease, any clinically significant intrauterine infection, a severe congenital abnormality, a persistent systolic blood pressure of greater than $60 \mathrm{~mm}$ $\mathrm{Hg}$, or had had seizures.

During the first week of life baseline haematological investigations were undertaken, which included a full blood count, ferritin, vitamin $\mathrm{B}-12$, and red cell folate concentrations. In addition, baseline urea and electrolyte measurements and urinanalysis were performed. These investigations were repeated immediately before the infant was 
discharged from hospital, being one to three days after the last dose. Sixteen infants eligible for entry into the study were randomised to the r-HuEpo group (Eprex, Cilag Ltd) and eight to the placebo group (4\% albumin solution) with a deliberate $2: 1$ double blind randomisation. The first nine infants received $50 \mathrm{U} / \mathrm{kg}$, the next nine infants received 100 $\mathrm{U} / \mathrm{kg}$, and the final six infants received $150 \mathrm{U} / \mathrm{kg}$ of $\mathrm{r}-\mathrm{HuEpo}$ or placebo twice a week subcutaneously into the buttock commencing after 7 days of age. r-HuEpo or placebo was administered until the infant was discharged home.

After each injection basic observations of the heart and respiratory rates, along with the temperature and blood pressure, were made and note was taken of any reaction to the study treatment. During the inpatient stay weekly measurements of the full blood count (Coulter S-plus), reticulocyte count (supravital stained film), and electrolytes (DAX 96) were made as is the normal policy on our unit. The ferritin (Becton Dickenson), vitamin B-12 (Becton Dickenson), and red cell folate (Becton Dickenson) concentrations were evaluated every two weeks. Haemoglobin F measurements were made by the method of Philips et al. ${ }^{14}$ In addition, at termination, blood was taken for erythropoietin antibodies (Bio Scientia).

The decision to give a blood transfusion to a study infant was made by the medical staff of the neonatal unit who were blinded to the randomisation. The unit policy at the time of the study was to transfuse a preterm infant who had a haemoglobin concentration less than $100 \mathrm{~g} / 1$ and who had symptoms consistent with those caused by anaemia. The symptoms and signs of anaemia included poor feeding, tachycardia, tachypnoea, apnoea, and pallor. Infants with a haemoglobin less than $80 \mathrm{~g} / 1$ were transfused even if asymptomatic. All infants received multivitamins and folic acid $(0.2 \mathrm{mg})$ from 2 weeks of age and iron $(6.25 \mathrm{mg})$ in the form of ferrous glycine sulphate from 4 weeks of age.

Throughout the study period, a record was taken of the number of transfusions given, the volume of blood transfused, and the amount of blood withdrawn for investigations. Follow up of the infants was carried out for one year, but only the first three months' follow up data are presented.

Statistical analysis was by Student's $t$ test for normally distributed data and the MannWhitney $U$ and $\chi^{2}$ tests for other data. Because of the small numbers of infants in each of the dose groups, the three dose groups were combined for all statistical analyses. Ethical approval for the study was obtained from the St Thomas's Hospital ethics committee.

At the outset of the study it was calculated that for a reduction in transfusions of $50 \%$ to be statistically significant at the $5 \%$ level with a power of $85 \%, 36$ infants should be recruited. However, due to the unexpected deaths of two infants from sudden infant death syndrome (SIDS, see results and discussion) the study was terminated prematurely after 24 infants had been recruited. This inevitably has reduced the power of the study particularly for the parameter of the number of transfusions given to each group.

\section{Results}

Twenty four infants were recruited to the study, with 16 in the r-HuEpo treated group and eight in the placebo group. There were no significant differences between the r-HuEpo and placebo groups for any variable (table 1) before the study. Twenty three infants completed the study, the other infant (number 3) was randomised to the r-HuEpo treatment group but was withdrawn from the study at 14 days of age to enable transfer to another hospital for maternal reasons. The data for this infant have not been included in the statistical analyses. Fifteen infants received a mean (SE) of $10.2(0.9)$ doses each of 96 $(10 \cdot 3) \mathrm{U} / \mathrm{kg}$ of r-HuEpo.

There was a significantly higher mean reticulocyte count in the r-HuEpo group of $106 \times 10^{9} / 1$ after week $2(p<0.01)$ when compared with the placebo group at $58 \times 10^{9} / 1$. The difference ( $95 \%$ confidence interval) between the means of the two groups was $48 \times 10^{9} / 1$ (19 to $\left.75 \times 10^{9} / 1\right)$. This difference was sustained until the administration of r-HuEpo was stopped at discharge (fig 1). The highest mean reticulocyte count in the r-HuEpo and placbo groups were the pretreatment values (120 and $\left.119 \times 10^{9} / 1\right)$. The reticulocyte count in the r-HuEpo group remained between 100 and $110 \times 10^{9} / 1$ being 1.8 times that of the placebo group $\left(50-60 \times 10^{9} / 1\right)$. After termination of treatment the mean reticulocyte counts did not differ significantly between the r-HuEpo and placebo groups at any stage during the three months' follow up (fig 1).

There was a significant fall in the mean ferritin concentration in the r-HuEpo treated group by $84 \mu \mathrm{g} / 1$ (19 to $149 \mu \mathrm{g} / \mathrm{l})$ to a mean of $88 \mu \mathrm{g} / 1$ compared with the placebo group mean of $172 \mu \mathrm{g} / \mathrm{l}$ at termination $(\mathrm{p}<0.02)$ of the active treatment phase (fig 2). There was a rapid decline in the mean ferritin from a mean pretreatment concentration of $214 \mu \mathrm{g} / 1$ to 101 $\mu \mathrm{g} / \mathrm{l}$ over the first four weeks until supplementation with iron was commenced. The rate of decline in the mean ferritin in the r-HuEpo group then slowed, though continued to fall and reached $88 \mu \mathrm{g} / 1$ at discharge. In the placebo group, the mean ferritin fell by

Table 1 Variables measured in 24 preterm infants studied before starting treatment. Results are mean (SE)

\begin{tabular}{lll}
\hline & $\begin{array}{l}r-\text { HuEpo } \\
(n=16)\end{array}$ & $\begin{array}{l}\text { Placebo } \\
(n=8)\end{array}$ \\
\hline No. of boys & 5 & 5 \\
Gestational age (weeks) & $29 \cdot 9(0 \cdot 3)$ & $30 \cdot 4(0 \cdot 6)$ \\
Birth weight $(\mathrm{g})$ & $1363(63)$ & $1502(97)$ \\
Apgar score $(5 \mathrm{~min})$ & $9 \cdot 1(0 \cdot 3)$ & $9 \cdot 3(0 \cdot 3)$ \\
Age at first dose (days) & $9(0 \cdot 4)$ & $8(0 \cdot 6)$ \\
Haemoglobin $(\mathrm{g} / \mathrm{l})$ & $157(7)$ & $157(7)$ \\
Packed cell volume & $0 \cdot 47(0 \cdot 02)$ & $0 \cdot 46(0 \cdot 02)$ \\
Haemoglobin $\mathrm{F}(\%)$ & $89(2)$ & $91(1)$ \\
Reticulocytes $\left(\times 10^{9} / 1\right)$ & $120(30)$ & $119(25)$ \\
Neutrophils $\left(\times 10^{9} / \mathrm{l}\right)$ & $5 \cdot 63(1 \cdot 46)$ & $3 \cdot 48(0 \cdot 44)$ \\
Platelets $\left(\times 10^{9} / \mathrm{l}\right)$ & $293(35)$ & $303(58)$ \\
Ferritin $(\mu \mathrm{g} / 1)$ & $206(33)$ & $213(55)$ \\
Vitamin $\mathrm{B}-12(\mathrm{mmol} / \mathrm{l})$ & $880(144)$ & $945(193)$ \\
Red cell folate $(\mu \mathrm{g} / \mathrm{l})$ & $733(38)$ & $808(105)$ \\
Systolic blood pressure $(\mathrm{mmHg})$ & $55 \cdot 3(1 \cdot 6)$ & $51 \cdot 0(3 \cdot 0)$ \\
\hline
\end{tabular}




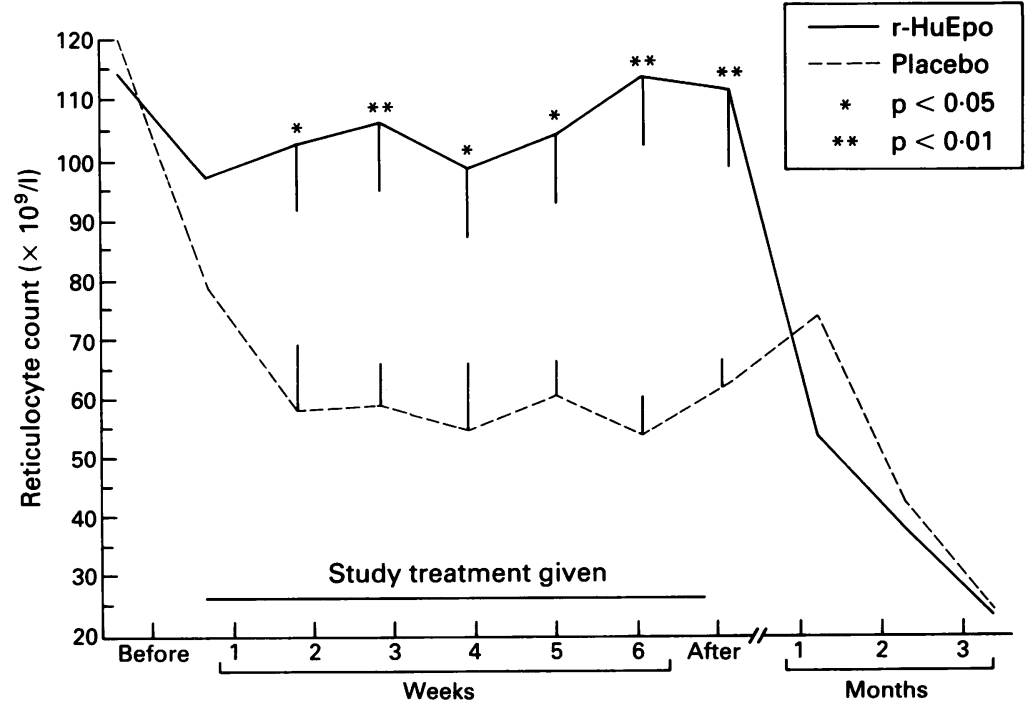

Weeks of treatment and months of follow up

Figure 1 The mean (SE) reticulocyte counts during treatment with subcutaneous $r$-HuEpo $(n=15)$ or placebo $(n=8)$ in preterm infants between 27 and 33 weeks'gestation during six weeks of treatment and three months of follow up. Significance of the r-HuEpo group against the placebo group is shown. After=1-3 days after cessation of treatment.

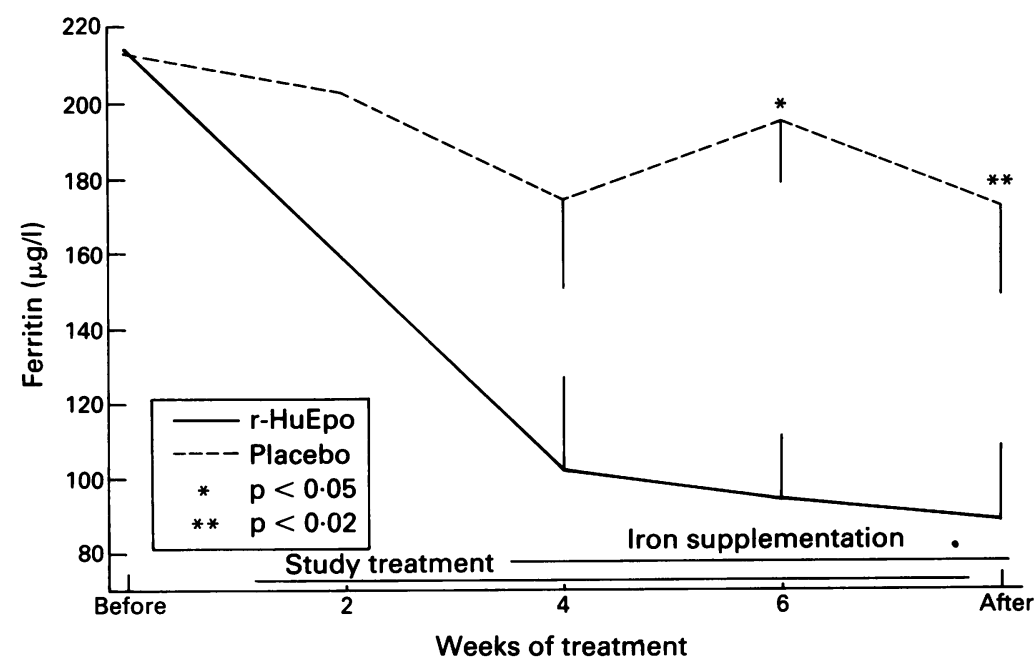

Figure 2 The mean (SE) serum ferritin concentrations in preterm infants between 27-33 weeks' gestation treated with $r-H u E p o(n=15)$ or placebo $(n=8)$. Iron supplementation $(6.25 \mathrm{mg})$ from 4 weeks of age. Significance of the $r$-HuEpo group against the placebo group is shown. After=1-3 days after cessation of treatment.

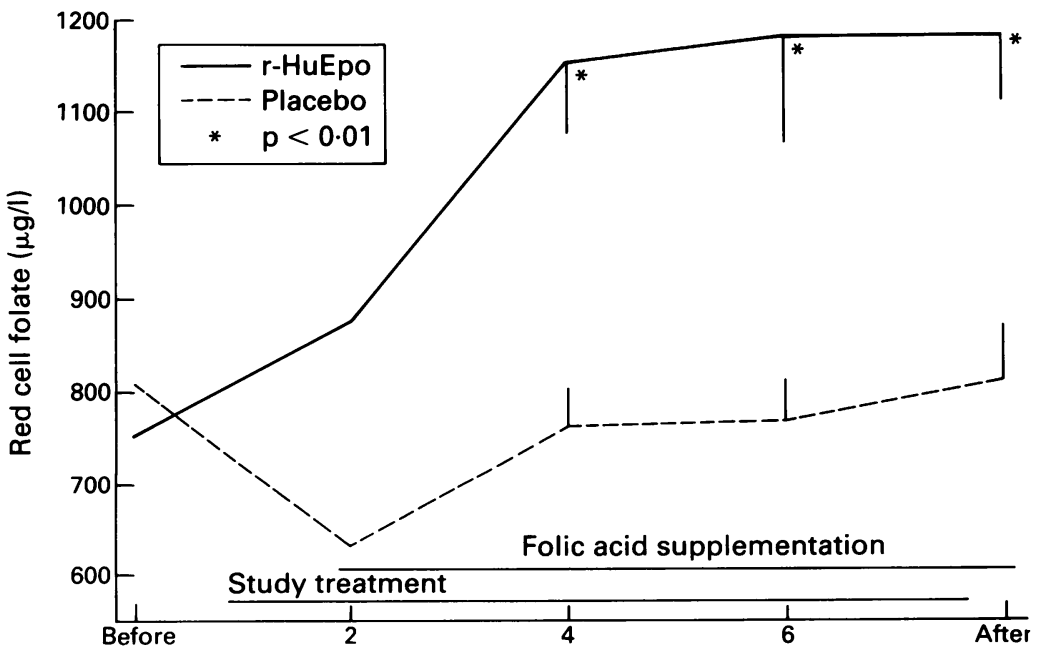

Weeks of treatment

Figure 3 The mean (SE) red cell folate concentrations in preterm infants between 27-33 weeks'gestation treated with $r$-HuEpo $(n=15)$ or placebo $(n=8)$. Folic acid $(0 \cdot 2 \mathrm{mg})$ was supplemented from 2 weeks of age. Significance of the r-HuEpo group against the placebo group is shown. After=1-3 days after cessation of treatment.
$38 \mu \mathrm{g} / \mathrm{l}$ to a mean of $174 \mu \mathrm{g} / \mathrm{l}$ and then remained constant after iron supplementation (fig 2). No infant was iron deficient at any stage as measured by the ferritin concentration.

After supplementation with folic acid, there was a significant increase in the mean red cell folate concentration by $390 \mu \mathrm{g} / 1$ (177 to $603 \mu \mathrm{g} / \mathrm{l})(\mathrm{p}<0.01)$ in the $\mathrm{r}$-HuEpo treated group to a mean of $1150 \mu \mathrm{g} / \mathrm{l}$ (fig 3), being $51 \%$ higher than in the placebo group at $760 \mu \mathrm{g} / 1$ from week 4 onwards (fig 3).

The difference in the fall of the percentage fetal haemoglobin at termination of the treatment compared with that pretreatment between the two groups was $19 \%(0.1$ to $38.7 \%)(p<0.05)$. There was a significantly higher concentration of fetal haemoglobin at the end of the study in the r-HuEpo group of $69 \%$ compared with the placebo group of $52 \%(p<0.05)$.

The number of infants requiring one or more transfusions was lower in the r-HuEpo treated group, with $47 \%$ requiring transfusions with a maximum of two, while $88 \%$ of the placebo group required transfusions, the maximum being three. The difference $(95 \%$ confidence interval) between those needing a transfusion in each of the r-HuEpo or placebo groups at $41 \%(-1$ to $83 \% ; p=0 \cdot 14)$, although large, does not reach statistical significance. A greater mean volume of blood was transfused in the placebo group, $19.6 \mathrm{ml} / \mathrm{kg}$, compared with the r-HuEpo treated group, $10.0 \mathrm{ml} / \mathrm{kg}$, the difference being $9.6 \mathrm{ml}(-1.6$ to $20.6 \mathrm{ml})$ does not reach statistical significance.

The mean systolic blood pressure in the r-HuEpo treated group of $81.9 \mathrm{~mm} \mathrm{Hg}$ was greater than in the placebo group at $75.7 \mathrm{~mm}$ $\mathrm{Hg}$ by $6.2 \mathrm{~mm} \mathrm{Hg}(-3.6$ to $16.0 \mathrm{~mm} \mathrm{Hg})$ at termination, which was not significant (table 2). At termination, the mean platelet count in the $\mathbf{r}-\mathrm{HuEpo}$ treated group was higher by $51 \times 10^{9} / 1\left(-55\right.$ to $\left.158 \times 10^{9} / \mathrm{l}\right)$ at $436 \times 10^{9} / 1 \mathrm{com}-$ pared with $385 \times 10^{9} / 1$ for the placebo group. The mean neutrophil count in the r-HuEpo treated group at termination, $2 \cdot 3 \times 10^{9} \Lambda$, was lower than the placebo group, $3 \cdot 1 \times 10^{9} / 1$, by $0.8 \times 10^{9} / 1 \quad\left(-0.4\right.$ to $\left.1.9 \times 10^{9} / 1\right)$ (table 2$)$. No infant had developed antibodies to $\mathrm{r}-\mathrm{HuEpo}$ at termination of the study. The weight increase in the r-HuEpo treated group at week $6,21 \cdot 1$ g/day, was greater by $1.3 \mathrm{~g} /$ day $(-3.6$ to 6.2 g/day) than the placebo group at $19.8 \mathrm{~g} /$ day.

During the study period and the first three months of follow up after discharge, there was no significant difference in the haemoglobin concentrations between the two groups, although the mean haemoglobin in the placebo group was below that for the r-HuEpo group for the first four weeks until blood transfusions were given. In addition, there was no evidence for a sudden fall in haemoglobin once administration of r-HuEpo had ceased.

ADVERSE REACTIONS

There were some adverse reactions during the treatment phase, but none could be ascribed to the r-HuEpo treatment (table 3). After 
discharge home, after the study medication had ceased, three deaths occurred, all of these infants had received r-HuEpo. One infant (number 6) developed acute volvulus of the gut two days after discharge home, and at laparotomy was found to have infarcted most of the large and small bowel. This infant had received $100 \mathrm{U} / \mathrm{kg} /$ week r-HuEpo. The other two infants (numbers 2 and 22) both died four weeks after discharge from hospital, and after a postmortem examination the cause of death was ascribed to SIDS. One infant received $100 \mathrm{U} / \mathrm{kg} /$ week and the second received $300 \mathrm{U} / \mathrm{kg} /$ week of r-HuEpo.

\section{Discussion}

Concern over the use of blood transfusions in preterm infants, and the frequent development of anaemia in otherwise well infants, has prompted the investigation of alternative treatments. ${ }^{15}$ Although the endogenous concentrations of erythropoietin in preterm infants is low, ${ }^{16-18}$ there appear to be adequate erythroid precursors both in the marrow and in the peripheral circulation, which are responsive to $\mathrm{r}-\mathrm{HuEpo}$ as demonstrated by cell culture techniques. ${ }^{5-7}$ It has been the practice in many units to wait until an infant with anaemia is symptomatic before blood transfusions are given. ${ }^{19} 20$ The use of r-HuEpo from an early stage might reduce the pathologically low haemoglobin concentrations seen in preterm infants, producing a situation mimicking the physiological fall in haemoglobin seen in term infants. ${ }^{1}$

Our study clearly demonstrates that the use of subcutaneous $r-H u E p o$, twice a week from 1 week of age, leads to a sustained increase in the reticulocyte count compared with the placebo group. In addition, the significantly increased concentration of red cell folate incorporated into the newly formed red cells in the $\mathrm{r}$-HuEpo treated group, and the dramatic and significant fall in the ferritin concentration, collectively suggest the presence of active erythropoiesis in the r-HuEpo treated group compared with the placebo group. The fact that the highest reticulocyte counts in either of the r-HuEpo or placebo groups were found in the pretreatment period just after birth is consistent with the understanding that endogenous erythropoietin is released during acute hypoxic stress at the time of delivery. 21

The reduction in the number of infants

Table 2 Variables measured in 23 preterm infants studied at the termination of treatment. Results are mean (SE)

\begin{tabular}{|c|c|c|}
\hline & $\begin{array}{l}r-H u E p o \\
(n=15)\end{array}$ & $\begin{array}{l}\text { Placebo } \\
(n=8)\end{array}$ \\
\hline $\begin{array}{l}\text { Haemoglobin }(\mathrm{g} / \mathrm{l}) \\
\text { Packed cell volume } \\
\text { Haemoglobin } \mathrm{F}(\%) \\
\text { Reticulocytes }\left(\times 10^{9} / \mathrm{l}\right) \\
\text { Neutrophils }\left(\times 10^{9} / \mathrm{l}\right) \\
\text { Platelets }\left(\times 10^{9} / \mathrm{l}\right) \\
\text { r-HuEpo antibodies } \\
\text { Blood removed }(\mathrm{ml} / \mathrm{kg}) \\
\text { Volume transfused }(\mathrm{ml} / \mathrm{kg}) \\
\text { Days to discharge } \\
\text { Systolic blood pressure }(\mathrm{mmHg}) \\
\text { Weight increase }(\mathrm{g}) \\
\text { Weight increase }(\mathrm{g} / \text { day })\end{array}$ & $\begin{array}{l}108(5) \\
0 \cdot 32(0 \cdot 02) \\
69(4 \cdot 7) \\
111(10) \\
2 \cdot 3(0 \cdot 2) \\
436(29) \\
\text { None } \\
25 \cdot 5(2 \cdot 6) \\
10 \cdot 2(3 \cdot 0) \\
44 \cdot 9(3 \cdot 2) \\
81 \cdot 9(2 \cdot 6) \\
840(80) \\
22 \cdot 3(1 \cdot 6)\end{array}$ & $\begin{array}{l}111(12) \\
0 \cdot 33(0 \cdot 03) \\
52(5 \cdot 9)^{*} \\
62(7) * * \\
3 \cdot 1(0 \cdot 7) \\
385(43) \\
\text { None } \\
26 \cdot 5(4 \cdot 6) \\
19 \cdot 2(5 \cdot 3) \\
47 \cdot 4(6 \cdot 0) \\
75 \cdot 7(4 \cdot 3) \\
730(90) \\
51 \cdot 0(3 \cdot 0)\end{array}$ \\
\hline
\end{tabular}

requiring one or more transfusions from $88 \%$ in the placebo group compared with $47 \%$ in the r-HuEpo treated group, along the significantly higher percentage haemoglobin $F$ at termination of the study, provides further support for the efficacy of r-HuEpo in stimulating erythropoiesis and reducing the need for blood transfusions in this patient group. The power of this study to demonstrate statistical significance for this large reduction in the need for transfusion is reduced due to the unexpected termination of the study after the deaths of the two infants from SIDS.

During the study period the mean haemoglobin concentration for the placebo group remained below that for the r-HuEpo treated group until week 4 (fig 4). The apparent increase in the mean concentration at week 5 for the placebo group and at week 6 for the r-HuEpo group are due to blood transfusions given to the infants in each group. A greater percentage of infants in the placebo group (88\%) were given transfusion compared with the r-HuEpo group $(47 \%)$, which has resulted in the mean haemoglobin concentrations between the groups not being significantly different.

The reported doses of r-HuEpo used so far have ranged from $37.5 \mathrm{U} / \mathrm{kg}$ twice a week ${ }^{13}$ to $700 \mathrm{U} / \mathrm{kg}$ in an alternate daily regimen, ${ }^{22}$ with several studies suggesting that there is a rise in the reticulocyte count. ${ }^{13} 22 \quad 23$ One double blind study used intravenously administered r-HuEpo and did not show any significant difference in the reticulocyte count, nor in the number of transfusion between the r-HuEpo and placebo groups. ${ }^{24}$ It has been reported that doses of $700 \mathrm{U} / \mathrm{kg} /$ week lead to an increase in the packed cell volume from 0.28 to 0.30 over a three week period. It is, however, still not clear what the optimal dose or frequency of administration of r-HuEpo should be.

In several studies, the r-HuEpo treatment has been commenced when the infant was

Table 3 Number and type of adverse and concomitant events seen during and after treatment in 23 preterm infants studied

\begin{tabular}{lll}
$r-$ HuEpo & $\begin{array}{l}\text { Placebo } \\
(n=15)\end{array}$ & $(n=8)$ \\
\hline
\end{tabular}

Events during treatment

ardiorespiratory:

Apnoea/bradycardia

Patent ductus arter
Chest infection

Gastrointestinal:

Abdominal distension

Bloody stools

Vomiting

Constipation

Haematology/biochemical

Biochemical rickets

Low neutrophil count

kin rashes:

Nappy rash

Others:

Lethargy

Oedematous legs

Ophthalmia neonatorum

Hernia

Events during follow up

General:

Wheezing

Infection

Hernia

Rash

Volvulus

SIDS

4

4

1

1

3

2

2

2

2
1 
several weeks old, or when the infant was already anaemic, in an attempt to prevent the need for transfusion. ${ }^{13} 24$ It may be that the delayed use of r-HuEpo has not provided sufficient time to allow correction of the anaemia before the onset of symptoms precipitated the use of transfusion. Our study commenced the treatment after the first week and even earlier use of $\mathrm{r}-\mathrm{HuEpo}$ in the first few days may well increase the efficacy.

For safety reasons we chose to commence with a low dose of $100 \mathrm{U} / \mathrm{kg} /$ week, rising to $300 \mathrm{U} / \mathrm{kg}$. There has been evidence from several sources that the use of erythropoietin in preterm infants may result in the development of neutropenia. Halpérin et al showed a fall in the neutrophil count, reaching a nadir at 56 days after r-HuEpo therapy at a dose of $75-300 \mathrm{U} / \mathrm{kg} /$ week, $^{13}$ and Ohls and Christensen showed neutropenia in the peripheral blood and reduced number of matured stored neutrophils in the bone marrow with doses of $700 \mathrm{U} / \mathrm{kg} /$ week. $^{22}$ This was not found in the study of Shannon et $a l^{24}$ although they found a significant inverse correlation with the value of the reticulocyte count in both the r-HuEpo and placebo groups. Although the absolute neutrophil count was slightly lower in the r-HuEpo treated group in our study this was within the normal range and was not significantly different from the placebo group, and no correlation was found between the reticulocyte and neutrophil counts. There have also been conflicting results from in vitro work, with some reports of reduced granulocyte production associated with the use of $\mathrm{r}-\mathrm{HuEpo},{ }^{25}$ while others have not found this. ${ }^{26}$

The deaths of two infants from SIDS one month after the termination of the active treatment in our study raises concern over the relationship with the use of r-HuEpo. The hypothesis that there may be development of a profound anaemia once the r-HuEpo treatment has ceased is not supported by the follow up evidence of haemoglobin concentrations (fig 4). There was no evidence that

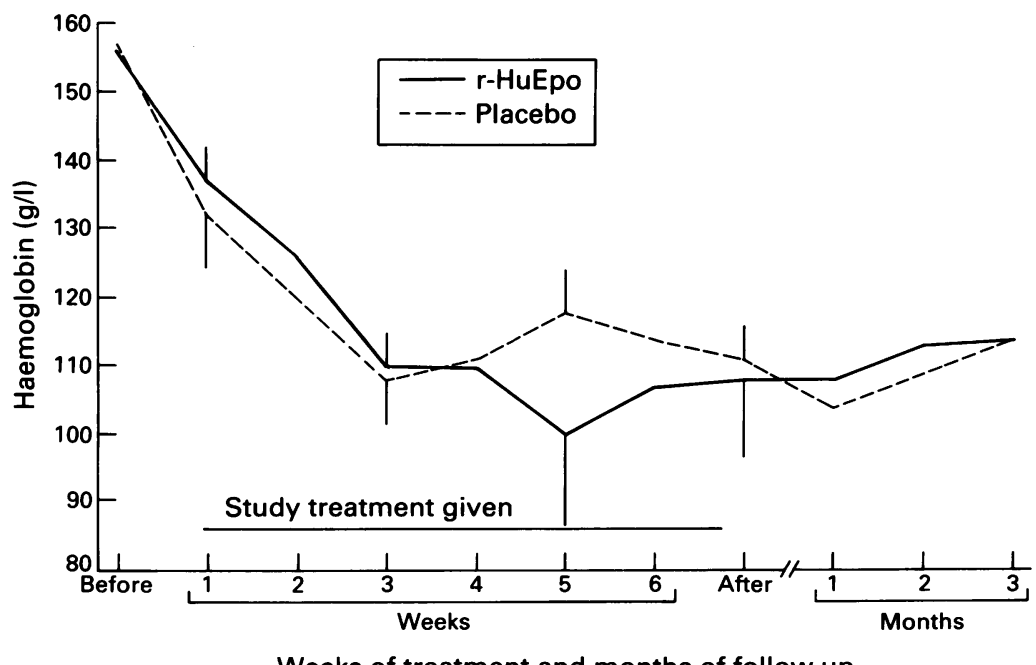

Weeks of treatment and months of follow up

Figure 4 The mean (SE) haemoglobin concentrations for preterm infants between 27 and 33 weeks' gestation treated with $r$-HuEpo $(n=15)$ or placebo $(n=8)$ during six weeks of active treatment and three months of follow up. any infant became anaemic after cessation of treatment.

A second hypothesis, that r-HuEpo may cause persistence of haemoglobin $\mathrm{F}$ and that, under adverse circumstances, there may be compromised delivery of oxygen to the tissues leading to death, is based on the tenous evidence that SIDS may be associated with persistence of haemoglobin $\mathrm{F}^{27}$ This association of SIDS with haemoglobin $\mathrm{F}$ has, however, not been found by all investigators. ${ }^{28} 29$ The two infants who died from SIDS in our study had lower haemoglobin F concentrations at termination of treatment than the mean for the r-HuEpo group and were more consistent with the placebo group, all being lower than the natural concentration of a mean of $72 \%$ in healthy term infants. ${ }^{30}$ There have been no other deaths due to SIDS associated with the use of r-HuEpo in any of the published studies.

This study clearly shows active erythropoiesis and a reduction in the use of blood transfusions for the anaemia of prematurity with the use of modest doses of r-HuEpo, although further studies with larger numbers of infants are required to clarify the optimal dose, frequency, and starting time for the prevention of this anaemia.

This study was supported by Cilag Ltd.

1 Dallman PR. Anaemia of prematurity. Annu Rev Med 1981;32:143-60.

2 Stockman JA III, Graeber JE, Clarke DA, McClellan K Garcia JF, Kovey REW. Anaemia of prematurity: determinants of the erythropoietin response. $f$ Pediatr 1984 105:786-92.

3 Brown MS, Garcia JF, Phibbs RH, Dallman PR. Decreased response of plasma immunoreactive erythropoietin to available oxygen in anaemia of prematurity. poietin to available oxygen

4 Brown MS, Phibbs RH, Garcia JF, Dallman PR. Post natal change in erythropoietin levels in untransfused premature change in erythropoietin levels in

5 Shannon KM, Naylor GS, Torkildson JC, et al. Circulating erythroid progenitors in the anemia of prematurity. $N$ Engl f Med 1987;317:728-33.

6 Emmerson AJB, Westwood NB, Rackman RA, Stern CMM, Pearson TC. Erythropoietin responsive progenitors in anaemia of prematurity. Arch Dis Child 1991 66:810-61.

7 Rhondeau SM, Christensen RD, Ross MP, Rothstein G, Simmons MA. Responsiveness to recombinant human erythropoietin of marrow erythroid progrenitors from infants with the 'anemia of prematurity'. $\mathcal{F}$ Pediatr 1988; 112:935-40.

8 Obladen M, Sachsenweger M, Stahnke M. Blood sampling in very low birth weight infants receiving different levels of intensive care. Eur $\mathcal{F}$ Pediatr 1988;147:399-404.

9 Wardrop CAJ, Holland BM, Veale AKE, Jones JG, Gray OP. Nonphysiological anaemia of prematurity. Arch Dis OP. Nonphysiological

10 Sandler SG, Grumet FC. Post transfusion cytomegalovirus infections. Pediatrics 1982;69:650-2.
ind

11 Stockman JA III, Garcia JF, Oski FA. The anaemia of prematurity. Factors governing the erythropoietin response. $N$ Engl F Med 1977;296:647-50

12 Jacobs K, Shoemaker C, Rudersdorf R, et al. Isolation and characterisation of genomic and $\mathrm{CDNA}$ clones of human erythropoietin. Nature 1985;313:806-10.

13 Halpérin DS, Wacker P, Lacourt G, et al. Effect of recombinant human erythropoietin in infants with anemia of prematurity: a pilot study. $\mathcal{F}$ Pediatr $1990 ; 116: 779-86$.

14 Philips HM, Holland BM, Abdel-Moiz A, et al Determination of red-cell mass in assessment and management of anaemia in babies needing blood transfusion. Lancet 1986;i:882-4.

15 Brown MS, Berman ER, Luckey D. Prediction of the need for transfusion during anaemia of prematurity. $\mathcal{f}$ Pediatr 1990;116:773-8.

16 Hågå P, Meberg A, Halvorsen S. Plasma erythropoietin concentrations during the early anaemia of prematurity. Acta Paediatr Scand 1983;72:827-31.

17 Keyes WG, Donohue PK, Spivak JL, Jones D Jr, Oski FA. Assessing the need for transfusion of premature infants Assessing the need for transfusion of premature infants
and role of haematocrit, clinical signs, and erythropoietin level. Pediatrics 1989;84:412-7. 
18 Saito $\mathrm{T}$, Urabe A, Uramoto $\mathrm{K}$, Hashimoto $\mathrm{Y}$, Takaku $\mathrm{F}$. Serum erythropoietin titres in the anaemia of premature Serum erythropoietin titres in the an
infants. $B r \mathcal{F}$ Haematol $1983 ; 54: 53-8$.

19 Strauss RC. Transfusion therapy in neonates. $\mathrm{Am} f \mathrm{Di}$ Child 1991;145:904-11.

20 Roberton NRC. Top up transfusions in neonates. Arch Dis Child 1987;62:984-6.

21 Finne PH. Erythropoietin level in cord blood as an indicator of intrauterine hypoxia. Acta Paediatr Scand 1966; 55:478-89.

22 Ohls RK, Christensen RD. Recombinant erythropoietin compared with erythrocyte transfusion in the treatment of the anemia of prematurity $\mathcal{F}$ Pediatr 1991:119:781-8.

23 Stewart G, Holland BM, Turner TL, Wardrop CAJ. Erythropoietin (rhEpo) in preterm infants: does it work? Br f Haematol 1991;3:(suppl 1):4.

24 Shannon KM, Mentzner WC, Abels RI, et al. Recombinant human erythropoietin in the anaemia of prematurity: results of a placebo-controlled pilot study. prematurity: results of a p

25 Christensen RD, Koenig JM, Viskochil DH, Rothstein G.
Down-modulation of neutrophil production by erythropoietin in human hematopoietic clones. Blood 1989; $17-22$.

26 Ward CS, Westwood NB, Emmerson AJB, Pearson TC. The in-vitro effect of high dose recombinant human erythropoietin on granulocyte-macrophage colony production in premature infants using a defined serum deprived cell culture system. Br f Haematol 1992;81:325-30.

27 Gillan GG, Gilbert EF, Moss RI. Elevated fetal hemoglobin levels in sudden infant death syndrome. $N$ Engl f Med 1987;316:1122-6.

28 Cheron G, Bachoux I, Maier M, Massonneau M, Peltire JY, Girot R. Fetal hemoglobin in sudden infant death syndrome. N Engl F Med 1989;320:1011-2.

29 Zielke HR, Meny RG, O'Brien MJ, et al. Normal fetal hemoglobin levels in the sudden infant death syndrome. hemoglobin levels in the sudden

30 Garby L, Siolin S, Vuille JC. Studies on erythro-kinetics in infancy. II The relative rate of synthesis of haemoglobin $\mathrm{F}$ and haemoglobin A during the first months of life. Acta Paediatrica 1962;51:245. 